\title{
Discursos juveniles sobre una ciudad excluyente y segregativa: de la experiencia a la reflexión
}

\author{
Roxana Quiroz Carranza \\ Universidad Autónoma de Yucatán \\ rquiroz@correo.vady.mx \\ Carmen Castillo Rocha \\ Universidad Autónoma de Yucatán \\ ccastillo@correo.vady.mx
}

Recibido: 9/7/2018 / Aceptado: 2/10/2018

doi: 10.26439/contratexto2019.n031.3889

\begin{abstract}
Resumen. Las ciudades son crisoles de movimientos y transformaciones que permiten el análisis desde múltiples ejes, y uno de los actores importantes de su devenir son los jóvenes. Las vivencias y prácticas de estos jóvenes generan discursos sobre el espacio que habitan, mismos que con frecuencia cuestionan los producidos por las instituciones, los medios de comunicación, las autoridades o los grupos sociales; de ahí, el objetivo fue analizar los discursos enunciados por jóvenes estudiantes de bachillerato que residen y estudian en una zona con altos niveles de desigualdad social de Mérida, México, en relación con el uso que hacen del espacio público y privado, y los significados que atribuyen a su territorio así como al resto de la ciudad. Describimos el contexto empírico (la ciudad) como un espacio de segregación y exclusión, y exponemos conceptos teóricos que permiten entender la diada ciudad-comunicación. Usando como metodología la semiótica social exponemos los discursos de los jóvenes, desagregados en cinco campos: dignificación del territorio, desplazamientos por la ciudad, usos del espacio público y privado, autoestima dañada, prácticas discriminatorias, racismo y estigma.
\end{abstract}

Palabras clave: jóvenes / ciudad / discurso / exclusión social 


\title{
Youth discourses about an excluding and segregationist city: from experience to reflection
}

\begin{abstract}
Aвstract. Cities are melting pots of movements and transformations that allow performing analyses from many points of view, and young people are one of the important actors of their evolution. The experiences and practices of these young people generate discourses about the space they live on, and they frequently question those produced by institutions, the media, authorities or social groups. Hence, the objective of this paper is to analyze discourses given by high school students who live and study in an area with high levels of social inequality in Mérida, Mexico. Said discourses are about their use of public and private space, and the meanings attributed to their territory and the rest of the city. We describe the empirical context (the city) as a space of segregation and exclusion, and present theoretical concepts that enable us to understand the citycommunication dyad. We used social semiotics as a methodology to explain young people's discourses which we disaggregated into five fields: dignifying the territory, traveling around the city, using public and private space, damaged self-esteem, discriminatory practices, racism and stigma.
\end{abstract}

Keywords: youth / city / discourse / social exclusion 


\section{Introducción}

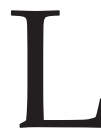

a ciudad de Mérida, capital del estado de Yucatán, México, es conceptualizada en este artículo como un escenario social, cultural y simbólico donde se desarrollan procesos de exclusión social y segregación socioespacial (Fuentes Gómez, 2005; Pérez Medina, 2010; Pérez y Gamallo, 2014). Tales problemáticas que identificamos en la Mérida contemporánea, la que grupos empresariales, representantes gubernamentales y estadísticas oficiales proclaman como una de las más seguras en un país afectado por la inseguridad, el crimen organizado, la desaparición forzada, la impunidad y la corrupción, son entendidas en el marco del estudio como constitutivas de las ciudades del siglo XxI, fragmentadas, divididas o segmentadas (Ziccardi, 2008), con "pocas posibilidades de cumplir sus funciones de integración social y hacer efectivos los derechos económicos, sociales, culturales y ambientales" (Ramírez-Kuri y Ziccardi, 2008, p. 24) de quienes las habitan.

Los aportes académicos producidos en torno de la distribución espacial de la pobreza y la marginación en Mérida ponen de manifiesto la desigualdad social existente y contribuyen a entender los significados construidos y comunicados por los jóvenes, sujetos de nuestro interés, a través de sus discursos. En esos significados se objetivan creencias, experiencias y sentimientos acerca del lugar donde transcurre su vida cotidiana y que reconocen como su territorio de pertenencia, así como su relación con el resto de la ciudad.

Mérida ha sido estudiada de forma multidisciplinaria a lo largo del siglo xx y en estas primeras décadas del xxi por urbanistas, antropólogos, sociólogos, historiadores, economistas, ecólogos humanos, biólogos y psicólogos, entre otros especialistas, lo que ha producido un abundante y diverso conocimiento sobre la urbe. De la década de 1980 a la actualidad, los intereses y amplia gama temática en las investigaciones abarcan múltiples objetos de estudio, aunque todavía se aprecian escasas contribuciones desde la comunicación para la comprensión de la ciudad. Sin embargo, hay acercamientos interesantes abordados desde las mediaciones, consumo de medios, análisis del discurso mediático, procesos de recepción, representaciones sociales, interacciones comunicativas y virtuales.

Un componente importante de estos análisis se ha situado en entender cómo se miran o son mirados los pobladores más desfavorecidos. Por ello, compartiendo este interés y preocupación, hemos ubicado nuestra atención en jóvenes que viven y estudian en la zona sur de la ciudad, nombrada por algunos medios de comunicación locales, en el ámbito académico e incluso de manera coloquial, como "el sur profundo" de Mérida, una zona segregada y excluida, con altos niveles de pobreza, marginación y desigualdad social (Quiroz Carranza, 2014; Castillo León, Guzmán Medina y Lugo Pérez, 2016). Consideramos, en 
concordancia con Ramírez-Kuri y Aguilar (2006), que “La ciudad es un incesante lugar de producción simbólica que es interpretado de manera rutinaria e inédita por aquellos que lo habitan" (p. 7). Y en ese sentido pensamos que los discursos juveniles nos arrojan significativas reflexiones y experiencias para el entendimiento complejo de la ciudad.

\section{Mérida: espacio de segregación y exclusión}

Las primeras interrogantes que nos interpelan como investigadoras son ¿cómo definimos a la ciudad de Mérida para, entonces, poder estudiarla desde la comunicación?, y ¿qué decisiones teóricas y conceptuales tomamos para explorar la segregación socioespacial y la exclusión social en el discurso juvenil? En primera instancia entendemos a la ciudad como un espacio concreto y vivo (Safa, 1993) en permanente construcción. Asimismo, como un territorio social e histórico conformado por quienes lo han habitado, pero también conformador de la vida de los seres humanos que hoy residen en él, es decir, un territorio que "al mismo tiempo construye, propicia o impide, genera o limita la vida de sus habitantes" (Safa, 1993, p. 288). Por tanto, se trata de una entidad multidimensional.

Para considerar que Mérida puede ser conceptualizada como segregativa y excluyente, es importante señalar que el término segregación social, de acuerdo con la urbanista Pérez Medina (2010), “desde sus inicios se ha utilizado para describir dinámicas sociales y espaciales de las ciudades" (p. 35), y ha sido ampliamente discutido por importantes autores y enfoques. Este debate nos permite identificar ciertos componentes de la segregación social para entender lo que acontece en el espacio urbano y asignar el sentido que le atribuimos en esta investigación: a) la concentración de grupos poblacionales en determinados sitios de la ciudad que comparten muchas características pero no son homogéneos; b) la diferenciación entre esos grupos y sitios, lo que lleva a establecer relaciones de jerarquía y poder, y c) esta diferenciación se manifiesta en la desigualdad, en todos los ámbitos de la vida social, de ciertos grupos y sitios. Para enfatizar en la distribución de los grupos sociales en el espacio territorial, hemos considerado utilizar el término segregación socioespacial (Pérez y Gamallo, 2014).

Respecto de la exclusión social, la socióloga y economista Alicia Ziccardi señala que la noción emerge de la sociología francesa en la década de 1970 y es integrada al discurso de la Unión Europea en la década de 1990, para hacer referencia a "nuevas prácticas económicas y sociales que surgen de las modalidades que adquieren el empleo y el nuevo régimen social" (Ziccardi, 2008, p. 83), tras la crisis del Estado Benefactor. De forma complementaria, Pérez Medina (2010) indica que el concepto es adoptado por el mundo académico y se han producido una gran cantidad de estudios sociológicos, antropológicos, 
económicos y políticos que abarcan cuestiones de género, racismo, desempleo, discapacidad y grupos vulnerables.

Esta autora comenta que inicialmente el concepto no contenía ningún sentido de clase ni territorial, pero con el tiempo se fue construyendo una noción "de los que están fuera del orden social establecido, diferenciados de los que están dentro de dicho orden. Su contraparte es la integración, entendida como la participación legítima y aceptada (que no es conflictiva) en las estructuras de la sociedad" (Pérez Medina, 2010, p. 33). En este sentido, los significados del término se han diversificado y la palabra, por un lado, "alude al conjunto de prácticas discriminatorias y desventajas sociales de que son objeto las clases populares en las ciudades" (Ziccardi, 2008, p. 28), y por otro, como señalan Safa y Aceves (2006), involucra la "existencia del otro extremo del camino", de los incluidos, de los no pobres, por lo que la exclusión es "una cara de la separación social, un resultado de la fragmentación, una consecuencia de la división y lucha entre los seres humanos" (p. 52).

Ante lo expuesto, partimos de la afirmación de que la ciudad de Mérida reviste la doble característica de segregativa y excluyente desde su fundación en 1542, como lo evidencia el uso diferenciado del espacio urbano en la traza del sitio donde fue construida durante la conquista española, lo que dio lugar a un patrón socioespacial centro-periferia (Hansen y Bastarrachea, 1984) ${ }^{1}$. Al analizar lo planteado por estos investigadores, Reyes (2003) encuentra que ese patrón experimentó importantes cambios derivados de la migración de las familias adineradas del centro hacia el norte de la ciudad, en el contexto del auge de la industria henequenera a principios del siglo $\mathrm{xx}$, con lo que se dio inicio a un nuevo patrón de distribución social de la población, mismo que acentuó el carácter segregativo del espacio urbano, bajo un nuevo esquema de distribución socioeconómica que corresponde al tipo norte rico-sur pobre. Este esquema se fortaleció durante las múltiples crisis agrícolas que culminaron con el derrumbe de la producción henequenera y su colapso en la década de 1990, lo que derivó en un importante flujo migratorio de pobladores rurales hacia Mérida, que se asentaron de forma irregular en terrenos ejidales y federales ubicados en la periferia de la ciudad, principalmente en el sur.

Nuevos análisis han hecho referencia a otro patrón de asentamiento derivado de las migraciones campo-ciudad. A partir de un estudio de la distribución

1 Hansen y Bastarrachea explican que el centro concentró a los representantes de los poderes político, militar, económico y religioso de la corona española; las manzanas circundantes albergaron a la población española y los barrios en la periferia fueron habitados por la población indígena al servicio de los españoles. 
espacial de la marginación en la ciudad, García, Oliva y Ortiz (2012) señalan que esta se puede identificar en toda la urbe porque es estructural, aunque varía su frecuencia en función de la zona: "en el norte de Mérida existen al menos siete colonias con niveles de muy alta marginación [...], lo que significa un mosaico más complejo y contrastante" (p. 89). En el texto, los autores también ubican una alta frecuencia de colonias con esta clasificación en la zona sur y consideran que esta distribución "da cuenta de un fenómeno de exclusión social y territorial" (p. 100). A este patrón lo estamos denominando de tipo estructural.

Aun cuando existe una diferencia clara entre un esquema de distribución socioeconómica de la población tipo norte-sur y otro estructural, en ambos casos se reconoce la existencia de numerosas colonias con alto grado de pobreza y marginación en el sur de la ciudad. Por tanto, podemos considerar que la polarización norte rico-sur pobre constituye una fuerza poderosa en las dinámicas de la ciudad y en las interacciones de sus habitantes (como se observa en las publicaciones periodísticas cotidianas y en el propio discurso de los jóvenes investigados), sin omitir la ubicación de colonias marginadas en otras áreas, colindantes con zonas residenciales, ni las nuevas transformaciones urbanas que hoy día se están viviendo en Mérida.

A diferencia de los factores que condujeron a los patrones de asentamiento antes señalados, expuestos por los estudiosos citados, podemos sugerir algunos que están contribuyendo significativamente en los cambios más recientes de la ciudad: a) la migración nacional derivada del clima de inseguridad que se vive en muchas de las entidades federativas del país y el reconocimiento de Mérida como una "Comunidad Segura" (Villafranco, 2016)²; b) la migración internacional de adultos mayores procedentes de Canadá y Estados Unidos que han decidido pasar sus años de jubilación adquiriendo casonas en el Centro Histórico de una ciudad tranquila y tropical, lo cual ha incrementado notablemente el valor de la propiedad en esta zona, y c) los cambios en la actividad económica y el auge del mercado inmobiliario en el norte de la ciudad (Bolio Osés, 2014), al que Franco Cáceres (2018) identifica como "capitalismo inmobiliario de interés trasnacional", constructor de infraestructura comercial de élite y habitación residencial, lo que profundiza la segregación y segmentación de los estratos sociales.

Según datos de Bolio Osés (2014), el crecimiento demográfico de Mérida, así como de otras cabeceras municipales y pequeños poblados aledaños, ha dado

2 De acuerdo con la nota periodística de Villafranco (2016) en la revista Forbes, el índice de "Las ciudades más habitables de México" que realiza el Gabinete de Comunicación Estratégica, considera tres indicadores (índice de calidad de vida, índice de satisfacción con los servicios e índice de satisfacción con el desempeño de alcaldes). 
lugar a un complejo sistema metropolitano que en 2010 concentraba ya a poco más de un millón de habitantes. La mitad de ellos, de acuerdo con Ramírez y López Santillán (2014, p. 14), "se asomó al siglo xxi en estado de pobreza”. Como complemento a esta afirmación, el Municipio de Mérida reporta en su diagnóstico estadístico y situacional de 2011 que "la mayor parte de la población económicamente activa del municipio recibe una remuneración por su trabajo entre 2 y 3 salarios mínimos" (p. 6)3. Se trata, pues, de un municipio con altos contrastes socioeconómicos que se manifiestan en la desigual calidad de vida de sus habitantes.

\section{Mérida: objeto de estudio de la comunicación}

El estudio de la ciudad en el campo disciplinario de la comunicación no es reciente, como lo señala Reguillo (1995), aunque las preguntas que lo han guiado han experimentado cambios significativos, particularmente porque los comunicólogos han incorporado en sus cuestionamientos elementos provenientes de otras disciplinas; por tanto, lo reconocemos como un objeto de estudio que puede construirse de manera transdisciplinaria. Sin embargo, hemos considerado pertinente hacer referencia a dos reconocidos investigadores que establecen vínculos claros entre los estudios urbanos y los estudios de comunicación.

El primero es Armando Silva, quien en su obra Imaginarios urbanos (2006) no solo describe las marcas sociales inscritas en territorios urbanos de Colombia y Brasil con propósitos comunicativos (como puede ser el grafiti), sino los imaginarios que se montan en tales inscripciones y que representan una ciudad como

resultado de muchos puntos de vista ciudadanos, que sumados, como se suman las cuentas imaginarias [...], dan como resultado que una ciudad también es el efecto de un deseo o de muchos deseos que se resisten a aceptar que la urbe no sea también el otro mundo que todos quisieran vivir. Y también el que viven y quieren que así sea. (Silva, 2006, p. 33)

Rossana Reguillo, en La construcción simbólica de la ciudad (2005), destaca la importancia de la comunicación como referente de la construcción de lo urbano al analizar un acontecimiento que cimbró las estructuras físicas, sociales y simbólicas de Guadalajara, México, tras las explosiones sucedidas en una zona densamente poblada en 1992. Al estudiar la relación ciudad-acontecimiento a través de los medios de comunicación, las asambleas, campamentos de damnificados, debates políticos, la calle y la vida cotidiana, pudo analizar las

3 El 2011 el salario mínimo diario de Yucatán era de MXN 56,70, equivalentes a USD 4,60 (paridad de ese año). 
significaciones, los discursos y prácticas, no solo de los afectados por el desastre, sino también de los "saberes expertos" argüidos por autoridades y otros agentes. Su interés por la ciudad ha permitido a la autora afirmar que ésta:

[...] es espacio de investigación prioritario y privilegiado, en la medida en que no es solamente el escenario de las prácticas sociales, sino fundamentalmente el espacio de organización de la diversidad, de los choques, negociaciones, alianzas y enfrentamientos entre diversos grupos sociales por las definiciones legítimas de los sentidos sociales de la vida. (Reguillo, 1995, p. 122)

En este mismo sentido, Margulis (2002) considera que la ciudad es una expresión de diferenciación social que de alguna manera emite señales a quienes la habitan o la visitan, que pueden ser de bienvenida o rechazo, de invitación o exclusión. Estas señales influyen en los itinerarios urbanos de los distintos sectores sociales que transitan por las ciudades. La diferenciación social - dice el autor- lleva a que algunos sectores manifiesten mensajes francamente hostiles para aquellos cuya presencia legítima en tal entorno es puesta en duda. Al fundamentar su perspectiva, Margulis sigue la línea de Barthes, quien escribe: "La ciudad es un discurso, y este discurso es verdaderamente un lenguaje: la ciudad habla a sus habitantes, nosotros hablamos a nuestra ciudad, la ciudad en la que nos encontramos, solo con habitarla, recorrerla, mirarla" (Barthes, 1993, pp. 260-261).

La afirmación de Barthes nos permite, entonces, identificar dos dimensiones del asunto: la ciudad que habla a sus habitantes y el discurso sobre ella de quienes la habitan. Para avanzar un poco más en esta dirección, Marta Rizo (2005) nos ofrece un estado del arte de la ciudad como objeto de estudio de la comunicología e identifica diversas líneas posibles de investigación, entre las que destacamos dos que explicitan la relación entre el espacio urbano y los posibles discursos que genera:

- Las relaciones entre el espacio urbano y la cultura política, considerando los procesos de producción, reproducción y transformación de imaginarios, representaciones y prácticas en torno a lo público y al poder.

- La multiplicidad de discursos sociales que coexisten en el espacio urbano, que explican las ciudades y construyen identidades y vida cotidiana; participación en lo público y acción colectiva. En ello van las prácticas y discursos sociales sobre la ciudad.

Ambas líneas se encuentran íntimamente relacionadas. Los discursos configuran la manera de ver y vivir la ciudad, en tanto que esta, como construcción humana, da cuenta de la cultura, la cual "remite a sistemas compartidos de códigos de la significación que hacen posibles la comunicación, el reconocimiento y la 
interacción" (Margulis, 2002, p. 515), es decir, la cultura hace posible la comunicación a partir de compartir códigos semejantes. En este contexto, la ciudad sería en sí misma un sistema de signos; un texto descifrable que puede ser "leído". Los habitantes de las ciudades tienen una competencia cultural para comprender su ciudad y desde luego para enunciarla a través de discursos.

Estos discursos pueden provenir de los múltiples sectores que conforman la ciudad. Pueden producirse y reproducirse desde los medios de comunicación masiva y entonces se mueven a manera de imaginarios. Estos imaginarios pueden tener algún componente empírico palpable que coincide con muchos otros elementos correspondientes a ópticas diversas y frecuentemente contradictorias, pero la coincidencia se da en aparente armonía. Otras veces los discursos provienen de instituciones y en tal caso están permeadas por valores arraigados, por miradas de lo que "debiera ser". A ellos se añade la subjetividad de quienes habitan en la ciudad y frecuentemente son blanco de los discursos provenientes de esos medios e instituciones.

$\mathrm{Si}$, de manera dialéctica, la ciudad es discurso y a la vez generadora de múltiples discursos sociales, atravesados por mediaciones económicas, políticas y culturales, entonces ¿cómo y desde dónde "leer" los discursos que provienen de jóvenes que viven en el sur profundo de Mérida? Al consultar trabajos con inquietudes semejantes, encontramos que Mariana Chaves (2017) analiza la distancia entre los discursos hegemónicos y los provenientes de jóvenes en condiciones de pobreza a partir de sus relatos biográficos. Ellos son habitantes de lo que el discurso hegemónico nombra la periferia de La Plata, Argentina, y califica de "villa" (que es despectivo), en tanto para los jóvenes es "mi barrio", el cual funciona como anclaje identitario desde el cual se mira e interpreta el mundo. La autora describe cómo las trayectorias de vida se van enlazando con marcas territoriales que se mueven según desplazamientos significativos, como las visitas al "centro" desde la periferia. A partir de ciertas representaciones se construyen límites que, al ser traspasados, marcan el relato de vida y también el encuentro con "lo otro" (ubicado en "otro" territorio) a diferencia de lo propio, y a partir de esa diferencia es que se monta el discurso de la autonomía. La autora identifica que el discurso de los jóvenes marca relaciones de poder que los ubican en situación de subordinación, excepto por la relación con sus pares, donde los discursos señalan complicidad, reciprocidad y lealtad.

En el caso de Luz Stella Martínez (2016), ella observa en su trabajo con jóvenes urbanos de Medellín, Colombia, que el territorio constituye una idea central y sobresaliente en sus discursos, identificando en él a dos sectores: los "otros", que son grupos armados, actores de la violencia, quienes de alguna manera norman el territorio por encima de lo legal, y "ellos", comunidad pacífica que resiste, 
reconociendo la existencia de "fronteras invisibles" que limitan su tránsito por los barrios. Los discursos de muchachas y muchachos versan sobre la vida cotidiana, los valores y el sentido de pertenencia de los lugares habitados, y más allá de lo habitual, apuntan hacia su deseo de ejercer denuncia social y colectiva y de subvertir un orden que consideran errado.

Por su parte, Quiroz Carranza (2014) encuentra que los jóvenes del sur de Mérida, al igual que las colonias donde viven, son objeto de múltiples percepciones negativas que los criminalizan. Maleantes, drogadictos y vagos son calificativos utilizados con frecuencia en las notas informativas, reportajes, editoriales y artículos de opinión que se difunden en los medios locales. "Se trata de una visión que estigmatiza y niega la existencia de jóvenes heterogéneos en esta zona de la ciudad" (Quiroz Carranza, 2014, p. 7). En su diversidad, dice la autora:

hay quienes se desempeñan como empleados, obreros, artesanos, en oficios, en el comercio formal e informal, prestan servicios domésticos, desarrollan labores agropecuarias, son estudiantes, catequistas, deportistas, músicos, artistas, profesionistas, etcétera, y muchas de estas actividades les permiten construir sus identidades juveniles. Sin embargo, el estigma los alcanza a todos en mayor o menor medida. (p. 24)

De igual forma, el sur de Mérida ha sido calificado por los medios de comunicación, funcionarios, políticos, líderes de organizaciones e incluso académicos, como "un lugar donde existen muchos problemas sociales", conformado por numerosas colonias "conflictivas". Desde esta perspectiva, se trata de un territorio signado por la violencia intrafamiliar, inseguridad, delincuencia, prostitución, niños abandonados o en condición de calle, pandillerismo, drogadicción, alcoholismo, migración y pobreza (Quiroz Carranza, 2014, pp. 22-23).

Nos parece importante incluir en el análisis que el discurso académico sobre Mérida, que ha hecho visible la exclusión social y la segregación socioespacial hacia la zona sur de la ciudad, ha sido "apropiado" de cierta manera, con fines políticos y electorales, por gobernantes y funcionarios locales. Eso explica grosso modo los titulares publicados en la prensa entre 2017 y 2018, por ejemplo: "Combaten brecha entre la Mérida del norte y la del sur" (Milenio Novedades, 23 de diciembre de 2017), "Derriban el muro que aísla el sur de Mérida" (Milenio Novedades, 11 de julio de 2017), o "Trabajos en el sur de Mérida. En febrero llegan recintos culturales y otras obras más" (Diario de Yucatán, 15 de enero de 2018).

Ante estos discursos construidos desde la alteridad, nos hemos propuesto analizar aquellos que enuncian los propios jóvenes del sur de Mérida, estudiantes de un bachillerato universitario fundado en la colindancia de dos colonias populares de esta zona de la ciudad. Entendemos que este discurso, como señala Reguillo (2005), constituye un sistema complejo en el que interactúan las 
dimensiones objetivas del mundo social y las dimensiones subjetivas de la experiencia. Las enunciaciones que hacen los jóvenes investigados acerca del territorio que habitan develan muchos aspectos relevantes de su interacción con la urbe y expresan eso que la autora denomina "el sentido desde dentro" (Reguillo, 2005, p. 19), construido a partir de sus experiencias y reflexiones.

Si bien el término discurso es definido desde posiciones teóricas y metodológicas diversas, lo cual implica que sea un concepto polisémico, para quienes estudiamos los procesos comunicativos provenientes de las interacciones sociales, es fructífero partir de la premisa de que los discursos se generan en dicha interacción y se comunican a través del lenguaje. Por tanto, podemos reconocer, con fines analíticos, un "texto" en lo comunicado por los sujetos de investigación, en el cual se "expresan modos de pensar y de sentir, conscientes o inconscientes, de la sociedad que los genera" (Coronado y Hodge, 2017, p. 67). De igual manera, reconocemos que ese "texto" se produce en un "contexto" social y cultural específico. Todo ello susceptible de ser analizado e interpretado con fines de generación de conocimiento, de intervención social o de cambio social.

\section{Una metodología para estudiar los discursos juveniles}

La estrategia metodológica que se ha utilizado en la presente investigación contiene una fase documental y una empírica. Para el estudio de la ciudad como espacio social segregativo y excluyente, y como escenario de encuentros y desencuentros entre actores sociales posicionados de manera diferenciada, se consultaron notas periodísticas, estadísticas demográficas y las obras de diversos especialistas sobre Mérida, como se observa en los apartados anteriores. Para la escucha y análisis del discurso que los jóvenes han construido sobre su ciudad, en particular la zona segregada y excluida donde viven y estudian, se hizo uso de la entrevista cualitativa o abierta, ya que constituye una "vía de acceso" a los aspectos de la subjetividad humana y una puerta de entrada a la realidad social (Vela, 2001).

Resulta indispensable hacer una breve referencia al tipo de institución educativa que constituye el bachillerato (un elemento importante del contexto) donde estudiaban los jóvenes investigados. Se trata de un proyecto fundado por la más importante universidad pública del estado de Yucatán, cuyo objetivo ha sido contribuir a la disminución del rezago social, educativo y económico de los habitantes del sur profundo de Mérida (Universidad Autónoma de Yucatán, 2009), a través de un enfoque que enfatiza en la interacción comunitaria y aplica un modelo educativo basado en competencias.

Las y los jóvenes que participaron en esta fase de la investigación, formaban parte de la primera generación que ingresó al bachillerato y cursaban el último año. Eran parte de una matrícula de 35 estudiantes, y solo un tercio aceptó 
explícitamente ser entrevistado, luego de la aplicación de un cuestionario sobre su condición juvenil y derechos humanos. Las entrevistas fueron realizadas en las instalaciones del bachillerato a 10 estudiantes, cinco hombres y cinco mujeres, de entre 17 y 24 años de edad, con el objeto de reflejar la proporción por sexo existente en el grupo.

Al ser la entrevista cualitativa o abierta una técnica que reconoce en el investigador y en el entrevistado a los dos protagonistas principales de una conversación regulada por un guion temático previo, los temas orientadores fueron las experiencias de vida cotidiana en sus colonias, su condición juvenil en la zona, el uso del tiempo libre, su relación con la ciudad y los "otros" diferentes, los usos sociales del espacio público y privado, y los discursos externos sobre el sur. En el transcurso de las entrevistas emergieron otras temáticas relevantes como su relación con algunas figuras de autoridad, entre ellas los servidores públicos.

De manera consistente con la perspectiva teórica y la metodología utilizada, los discursos generados en las entrevistas se analizan desde la propuesta de la semiótica social que, de acuerdo con Coronado y Hodge (2017), busca enfatizar en las funciones y usos sociales de los sistemas de significado, las complejas interrelaciones entre estos sistemas semióticos en la práctica social, así como los factores que intervienen en sus constitución y metas. Optar por esta perspectiva nos ha representado considerar que "los significados son creados y transformados colectivamente en la interacción social” (Coronado y Hodge, 2017, p. 67). Con estos elementos como orientadores, identificamos en los discursos juveniles (el material empírico), a partir de nuestro marco de referencia y elección metodológica, ciertas categorizaciones relacionadas con la ciudad como espacio donde se viven experiencias de exclusión social, pero también como escenario de diversas prácticas sociales. Estas son la dignificación del territorio, su desplazamiento por la ciudad, el uso del espacio público y privado, la autoestima dañada, las prácticas discriminatorias, el racismo y el estigma.

\section{Resultados: los discursos juveniles}

Vistos en su más amplia dimensión, los discursos de los jóvenes investigados apuntan, por un lado, hacia una reivindicación positiva de las colonias donde viven, aun cuando hablan de las carencias y necesidades de la zona, así como la violencia y el vandalismo cotidianos. En este mismo sentido, valoran la solidaridad de sus vecinos e incluso la estética de ciertos sitios. Por otro lado, cuestionan los estereotipos existentes sobre el sur, porque afectan su dignidad como personas y limitan sus oportunidades de crecimiento. También hacen referencia a diversos aspectos negativos, entre ellos la autoestima dañada de la gente del sur, los actos de discriminación y racismo que han experimentado por vivir 
en esta parte de la ciudad y el estigma que de alguna manera los condena: "en el sur acuchillan", ya que los expone a múltiples prejuicios, formas de rechazo y criminalización.

En cada categoría analítica encontramos significados donde estos jóvenes expresan su cuestionamiento a los discursos hegemónicos que criminalizan al sur; que evidencian la desigualdad socioeconómica, simbólica y por razones de género; que ofrecen resistencia a los estereotipos sociales y al estigma, pero, al mismo tiempo negocian o se relacionan en aparente armonía con algunos discursos mediáticos y valores institucionales que los llevan a establecer distinciones entre los habitantes del sur.

\title{
Dignificación del territorio
}

Entre los significados que buscan salirse de una visión homogeneizadora del sur como una zona de peligro (criminalización) están los de " $\mathrm{A}$ " (hombre, 18 años), quien señala que hay zonas riesgosas donde asaltan, pero esto no puede hacerse extensivo a todo el sur. En esta misma tónica está "J" (mujer, 19 años), quien considera que "justos pagan por pecadores" al extenderse la creencia de que en el sur todos son vándalos, por lo que se han creado estereotipos negativos. Incluso sostiene que también hay vandalismo en el norte de la ciudad, pero se oculta por alguna razón o se responsabiliza a la gente del sur por los actos delictivos que se cometen allá.

\begin{abstract}
"J": Una vez salimos tarde [del bachillerato] y estaba un antimotín y nos dijo: "muchachos ya agarren sus camiones porque después vienen vándalos y no les vayan a faltar el respeto a las señoritas, así que apenas pare su camión por favor que se vayan, porque si no, no va a ser mi culpa - dijo-, yo se los estoy advirtiendo". Entonces justos pagan por pecadores, porque sí, de que hay, hay, pero no es todo, no es todo así en general. Y como dicen, en todos lados hay, hasta en el norte hay vándalos, en todos lados, pero no sé por qué han estereotipado tanto, tanto al sur. Tal vez porque, no sé, allí lo esconden y aquí no, o va gente ahí y dicen que es del sur, no sé, pero sí sé que hay muchas gentes que lo hacen y que sí, de alguna manera es real, pero no quiere decir que todos sean así.
\end{abstract}

En su propósito de dignificar al sur, "F" (mujer, 17 años) establece negociaciones entre los propios significados y lo que otros dicen de la zona. Destaca la comunicación y solidaridad con los vecinos más próximos a su casa y sitúa los problemas de vandalismo en otros puntos de su colonia: "Yo vivo en la avenida, los problemas están más en el fondo". Para " $F$ " no representa problema alguno el sitio donde se vive, sea el norte o el sur de la ciudad, el meollo de la cuestión está en la capacidad de superación y en los deseos de hacerlo; la diferencia la sitúa en el ámbito de las actitudes, de los valores. Por tanto, hace una distinción 
entre los "buenos" sureños y los "problemáticos" mediante una ubicación espacial diferenciada.

\begin{abstract}
"F": Por las casas que rodean mi casa, considero que tenemos buena comunicación con los vecinos, nos llevamos bien. Cuando llega Navidad festejamos con ellos, rompemos la piñata, pero el problema es más en los extremos [...] pero creo que para salir adelante no depende del lugar donde vivas, de dónde eres. Si tú tienes la capacidad y las ganas de salir adelante, qué importa que seas del norte o seas del sur.
\end{abstract}

Consideramos que en esta restitución de la dignidad al sur no hay idealización sino reflexión y cierta cuota de oposición y reclamo a las generalizaciones condenatorias que conllevan a una diferenciación social. " $\mathrm{D}$ ” (hombre, 24 años) señala que hay fraccionamientos y parques bonitos, gente trabajadora y solidaria, y se practica el deporte. También hay vandalismo, pero este se ha venido reduciendo con el tiempo por la intervención de la ley y la recapacitación de los jóvenes involucrados; por tanto, afirma que es un lugar bueno para vivir tranquilamente.
“D”: [...] desde que tengo uso de razón he vivido allá siempre. [...] Si usted viera el fraccionamiento, pues no está feo, está bonito; de hecho, lo único que le falta allá es internet al parque. Lo que le da un mal aspecto es que igual hay grafitis, pero el parque ha servido como un sustento para algunas familias cer- canas porque allá ponen tianguis. Y el tianguis que ponen no se ve tan feo, o sea, tiene sus puestecitos y todo, apenas se termina todo el evento que haya, se van, limpian sus cosas y se van. [...] Los vecinos, aunque hay excepciones, sí se apoyan, digamos que contribuyen para cooperar, para que no pase a mayores [...] digamos que es un lugar bueno, es un lugar que se hizo para que tú puedas vivir tranquilamente.

En el mismo sentido, "C" (hombre, 17 años) desacredita a los que hablan sin conocer al sur, sin haberle dado una oportunidad a esta zona de la ciudad. Para él en cualquier punto de Mérida hay gente buena y mala, honrada y deshonesta, criminal e inocente, independientemente de los recursos económicos que posean y el lugar donde se viva.

"C": Pues yo creo que no se han dado la oportunidad de conocer el sur. Yo siempre he dicho que una persona que opina sobre algo realmente debe saber de lo que está hablando, conocer esa cosa o ese fenómeno del que está dando opinión. Y con respecto a eso, sí se nos ha catalogado mal. [...] creo que en todos los lados hay personas que son malas, hay personas que son buenas, hay personas que son honradas, hay personas que no, hay personas que matan y hay personas que no. Creo que eso en todos lados va a haber y creo que tanto en el norte como en el sur o en el oriente, siempre hay ese tipo de personas, independiente de las posibilidades económicas que tenga. 


\section{Desplazamiento por la ciudad}

Los desplazamientos por la ciudad de los jóvenes investigados están condicionados por su situación económica, el género, su categoría juvenil y estudiantil y disponer de un cierto tiempo libre. El análisis del uso del tiempo libre o de ocio es fundamental desde los estudios de juventud, ya que allí -como coinciden los juvenólogos - se construyen y expresan muchos aspectos distintivos de los jóvenes, fuera de las normas y vigilancia del mundo adulto. En los discursos es posible identificar elementos asociados con la exclusión social, con la organización social de la ciudad y con su condición juvenil.

Para estos jóvenes el tiempo libre es limitado ya que la realización de actividades escolares, del hogar e incluso laborales les consume gran parte del día. Señalan que en el poco tiempo libre del que disponen les gusta principalmente convivir (divertirse, "relajear", ir a fiestas, salir a las plazas, ir al cine, salir de paseo, ir a la playa) con sus amigos(as) y con los novios(as). Sin embargo, palabras como "plazas", "cine", "paseo", indican analíticamente salir fuera de un territorio segregado y excluido, ya que en esta parte de la ciudad no existen ni plazas comerciales, ni salas cinematográficas - hoy convertidos en importantes espacios de encuentro e interacción entre jóvenes-. De igual forma, "salir a pasear" implica contar con recursos económicos, permisos de los padres y la existencia de lugares para la recreación en otros puntos de la ciudad, diferentes a los parques y canchas en malas condiciones de las colonias donde viven, e incluso salir fuera de Mérida, aunque esto sea algo excepcional en su vida cotidiana.

“L” (mujer, 17 años): [...] ir al cine, es muy extraño, esta zona es muy alejada de esos tipos de paseo a diferencia de otras colonias, que por ejemplo escuchas que me fui al cine ayer, o que no sé qué, como que no es muy común escuchar que alguien se vaya al cine así, con sus amigos o algo así. Mayormente los que juegan futbol sí se alejan un poco, pero en cuestiones de ir a torneos [...].

En este tópico hay excepciones que se explican desde la diversidad de prácticas, desde las señales simbólicas de la ciudad que influyen en los itinerarios, desde el deber ser diferenciado culturalmente entre hombres y mujeres, pero también desde los condicionamientos expuestos líneas atrás. Estos son los casos de "S" (hombre, 19 años), " $\mathrm{D}$ " (hombre, 24 años) y "A" (hombre, 18 años). El primero asistió al concierto que el músico e intérprete inglés Elton John dio en la zona arqueológica de Chichén Itzá en abril de 2010. El segundo ha recorrido diversas localidades del estado, en el contexto de los bailes populares o simplemente para degustar la comida típica y conocer "más allá" de la ciudad. El tercero asiste a "tocadas" en foros culturales del centro, oriente y poniente de la ciudad para escuchar música ska, rock, punk y heavy metal. 
Es significativo que en los discursos de los jóvenes aparezcan algunos de sus compañeros y compañeras de la escuela como acompañantes en estos desplazamientos, por lo que es posible considerar que la interacción en el ámbito escolar ha fortalecido sus inquietudes e intereses por explorar otros lugares, así como la seguridad y confianza en sí mismos para hacerlo. También convoca a reflexión su condición juvenil, particularmente asociada al ejercicio de su independencia (entendida como el uso de su libertad), y su capacidad de agencia (entendida, en un sentido restringido, como la capacidad de tomar decisiones propias), en esta etapa de la vida, en la que buscan romper el acceso desigual a la ciudad y apropiársela.

\section{Uso del espacio público y privado}

Al igual que para el desplazamiento por la ciudad, la diferenciación por razones de género también interviene de forma importante en el uso del espacio público y privado. Los hombres, en su tiempo libre, optan principalmente por el deporte (básquetbol, béisbol, fútbol, salir a correr), lo cual pone el énfasis en los espacios públicos (canchas, deportivos) existentes en sus colonias. Cuando mencionan que les gusta también estudiar, leer, ver documentales, jugar videojuegos, estar en las redes sociales, charlar, hablar por teléfono, significa que sus actividades son múltiples y parte de ellas también se realiza en el espacio privado, donde se conectan mediante las nuevas tecnologías, a las que acceden aun con las limitaciones económicas propias de la familia.

El énfasis de las mujeres está colocado en internet (navegar, conocer nuevas personas y lugares, estar en las redes, usar la tecnología), cuya conexión se realiza en el espacio privado (el hogar) y eventualmente en la escuela. Sus discursos también expresan una gran diversidad de actividades (escuchar música, cantar, platicar, ver películas), pero gran parte de ellas son realizadas en estos espacios privados donde están involucrados dos tipos de actores principales: los pares y la familia, sea nuclear o extensa. Cuando comentan que les gusta ir a las plazas, al cine, al parque, a la playa o salir de compras, es evidente que también se desplazan más allá de sus colonias con propósitos de recreación, pero en menor proporción, frecuencia y distancia geográfica.

En sus relaciones con el espacio público, las jóvenes manifiestan sufrir con frecuencia de malos tratos y acoso sexual. Por ejemplo, tienen problemas con los conductores del transporte urbano que no les respetan el $50 \%$ de descuento que debían otorgarles por ser estudiantes (prestación social vigente) y, peor aún, los conductores evitan hacerles la parada para que suban al autobús. " $\mathrm{R}$ " (mujer, 18 años) recuerda: “detienen el camión aparentando que me darán parada y, cuando me aproximo para subir, ellos arrancan el camión [...] no tienen ese respeto, mayormente los camioneros no respetan a los estudiantes". Llegó a quejarse 
un par de veces al número telefónico donde se denuncian estas irregularidades, a sabiendas de que no iba a obtener ninguna solución. Respecto del acoso callejero, " $R$ " comenta: "a veces he estado saliendo de la escuela y ahí, esas personas te están diciendo un montón de groserías, hasta puerquezas [...] yo estoy caminando libremente y ellos me vienen a agredir". Esta joven tiene temor de confrontar a los agresores que generalmente se encuentran en grupo, le faltan al respeto sin que intervenga la ley y la hacen sentir insegura y temerosa.

En sus discursos las jóvenes también expresan que en sus padres existe la idea de que los lugares públicos son espacios que pueden ser hostiles para las mujeres, motivo por el cual restringen los permisos incluso para realizar actividades deportivas; se les juzga de forma condenatoria por el solo hecho de visitar una cancha deportiva. "J" (mujer, 19 años), quien practica cotidianamente el básquetbol, narra que ha tenido que luchar en su casa por el "derecho a tener permisos". Esta inequidad con relación al uso y recursos de los espacios públicos destinados al deporte, la encuentran incluso en la propia escuela.

Para los jóvenes varones, en cambio, el deporte representa una opción para moverse fuera de su territorio al asistir a competencias y encuentros con otros equipos deportivos. El béisbol es el deporte más popular por estos lugares, pero los jóvenes también dicen practicar vóleibol, fútbol, básquetbol y ciclismo, mismos que pueden realizarse en las instalaciones deportivas escolares y municipales cercanas, pero para asistir a eventos artísticos y culturales tienen que desplazarse a sectores lejanos en la ciudad. Conviene señalar también que otro espacio relevante de esparcimiento, aprendizaje y espiritualidad son los grupos confesionales de muy diversos cultos, establecidos en distintos puntos del sur de la ciudad.

Sin embargo, su acceso con mayor independencia al espacio público los expone a prácticas arbitrarias (cateo y maltrato) por parte del aparato policial de la ciudad. Sin haber vivido experiencias directas, los entrevistados han presenciado en sus entornos inmediatos actos de injusticia contra otros jóvenes, portadores de identidades juveniles estigmatizadas y criminalizadas, como la que describe " $\mathrm{C}$ " (hombre, 17 años) en párrafos posteriores.

\section{La autoestima dañada}

La valoración de su territorio de pertenencia les resulta conflictiva. Durante las entrevistas expresan mayor facilidad para identificar los aspectos negativos de la zona, aun cuando la dignifican en otros momentos de las entrevistas. Se trata de un flujo constante entre la negociación y la oposición por legitimar los sentidos sociales de la vida, como señala Reguillo (1995). Consideran que muchas de las cosas que dicen los periódicos son ciertas, en particular las que se refieren a prácticas vandálicas (parques recién remodelados que son cubiertos de grafitis, robo 
del mobiliario, destrucción de la infraestructura). “B” (mujer, 18 años) piensa que en el sur hay personas que quieren salir adelante pero no pueden y otras que pueden, pero no quieren; “L” (mujer, 17 años) ubica la problemática en la falta de autoestima entre las personas, aunque se opone a la crítica de la sociedad que no busca soluciones propositivas para el sur y en cambio genera conflicto.

"B": Yo reconozco que en el sur hay personas que quieren salir adelante, pero definitivamente no tienen los medios para hacerlo, son personas cuyos papás no les pueden costear sus estudios, entre otras cosas. Pero hay personas que sí pueden, y no aprovecharon la oportunidad que se les dio. [...] Y basta con remodelar un parque en el sur para que en 15 días ya lo hayan grafitiado o ya se hayan robado parte del mobiliario que hayan puesto allá. Desafortunadamente, hay personas, hay malos elementos en el sur.

“L": Yo pienso que falta autoestima para la zona sur. No hay una pequeña inyección de fórmula positiva para que esas personas se sigan estimulando y logren salir de esos problemas que llevan. Porque por mi casa hay mucho vandalismo, y puedo decir cosas negativas, pero si yo no hago algo al respecto para que eso se reduzca, la marginación siempre va a estar presente y ante eso como que la sociedad no se da cuenta y empieza a generar más conflictos y más conflictos, en vez de ir eliminando y mitigando cada problema que vaya surgiendo.

El "yo pienso" es una señal ineludible de reflexión sobre un tema altamente sensible entre los jóvenes entrevistados. En particular, el discurso de "L" nos permite saber que la falta de autoestima devalúa a las personas, las vulnera y contribuye a la legitimización de muchos de los discursos mediáticos e institucionales que se producen sobre el sur y sus habitantes. Poco afortunado resulta el rol que juega la sociedad en la solución de los conflictos, así como el escaso énfasis de los medios de comunicación en las prácticas positivas (solidaridad, comunicación, cooperación) que se desarrollan en el sur de la ciudad.

\section{Prácticas discriminatorias, racismo y estigma}

"A" (hombre, 18 años) afirma categóricamente: "En Mérida hay mucho racismo". Este racismo se expresa en la actitud discriminatoria que la policía meridana tiene con los jóvenes del sur por sus vestimentas y arreglos, pero también por el aspecto físico de quienes portan ciertos estilos juveniles (morenos, chaparritos). En su discurso aparecen identidades juveniles estigmatizadas y criminalizadas que se desarrollan en ámbitos espaciales diferentes. El sur está más asociado al estilo cholo y el centro de la ciudad con los neohippies ${ }^{4}$.

4 Al respecto consultar las obras ;A la brava ése! de José Manuel Valenzuela Arce (1988) y Bandas juveniles. Perspectivas teóricas de José Encinas Garza (1994). 
Para "A", el aparato policial discrimina y hostiga desconociendo lo que piensan los jóvenes portadores de esas identidades, es decir, su ideología. Solo actúa en función de la apariencia. Esta apariencia es estereotipada por los agentes del Estado y conlleva una distinción entre los jóvenes del norte rico ("bien arreglados") y los jóvenes del sur pobre, que finalmente se convierte en discriminación, racismo y estigma. Frente a la primera clase de jóvenes, la policía no hace nada ("cree que es la clase alta, viene del norte"), pero en relación con la segunda los hostiga y agrede ("los mal mira, porque la zona sur ha sido muy despreciada entre ellos").

" $\mathrm{A}$ ": Yo me he fijado que, por ejemplo, que cuando alguien pasa bien arreglado, el policía no hace nada, cree que es la clase alta, viene del norte. No pueden ver a un chavo así, con sus camisas holgadas y todo el rollo, dicen que es del sur, lo mal mira, porque la zona sur ha sido muy despreciada entre ellos, porque ha sido, no sé, lugar de abandono donde se refugian las personas que son "el mal" de la sociedad, son "el terror" de la sociedad, y la policía se queda mal mirando a los cholos. Otros son los hippies, solamente es por su pelo. A veces los policías, sin saber lo que para ellos significa, solamente se quedan mirando y dicen: "Ese es maleante y viene del sur", y nada que ver. No sé, conozco a hippies que son de otra parte del continente y otra parte de América y todo el rollo, pero igual, los policías solamente quieren, no sé, buscan ser racistas, al no tener claro que están para cuidar a los ciudadanos, ya sea su cultura, sus ideologías, su momento de convivencia entre ellos, en la misma plaza ${ }^{5}$, todo eso [...].

$\mathrm{Al}$ igual que en la experiencia de " $\mathrm{A}$ ", en la de " $\mathrm{C}$ " (hombre, 17 años) también aparecen los policías y antimotines como autoridades agresoras en los espacios públicos y los vulnerados otra vez son los jóvenes portadores de identidades estigmatizadas y criminalizadas. Desde la perspectiva de " $\mathrm{C}$ ", las obligaciones de la policía debieran ser cuidar, proteger, dar seguridad y garantizar el orden en casos donde haya problemas reales. No ejercer violencia y discriminación contra las personas solo por su apariencia física.

“C": fuimos al parque, estábamos jugando [...] vi que se acercó la patrulla para ver, para vigilar. Vi que se acercaron, y enseguida los pegaron a la malla [que rodea al parque], les dijeron que alcen sus manos, que los iban a revisar. Y sí eran chavos así vestidos con pantalones anchos, pelos largos y todo eso. A mí me pareció incorrecta esa manera de actuar de la policía, porque creo que realmente los problemas que deberían atacar o vigilar, esos no lo hacen. [...] Eso me molestó mucho porque yo no discrimino, trato de evitar eso de discriminar personas solo por su apariencia ni nada; esa vez me pareció muy injusto

5 "A" se refiere a la plaza principal de Mérida, identificada oficialmente como la Plaza de Armas, situada en el corazón de la ciudad. 
porque ellos solo estaban conviviendo, estaban comiendo entre ellos porque habían jugado fútbol, estaban comiendo y platicando.

En estas experiencias de discriminación, agravio, maltrato y racismo, sin "haber dado motivos", observadas por los jóvenes investigados tanto en el sur como en el centro de la ciudad, aparece el aparato policial como vigilante de normas y valores hegemónicos que "deben" orientar el uso de la ciudad por quienes la habitan; permisivos a las relaciones desiguales entre los diferentes sectores sociales que la conforman, y reproductores, en última instancia, de la exclusión social. Pero también se manifiesta el severo cuestionamiento de los jóvenes a los excesos en el ejercicio del poder, a la injusticia, y su exigencia de respeto a los derechos de las personas.

\section{Discusión}

Si bien entendemos a la ciudad de Mérida, Yucatán, como un espacio en permanente construcción, lo que ha dado paso a diferentes patrones de organización socioespacial en sus casi 500 años de historia, consideramos que estos patrones comparten la doble característica de excluyentes y segregativos. Este tipo de configuración afecta a los diversos grupos poblacionales que viven la ciudad, porque tiene un gran impacto en su calidad de vida, en el uso que hacen del espacio urbano y en la multiplicidad de discursos sociales que se construyen desde dentro y fuera de sus territorios, en los que juegan un papel significativo los imaginarios mediáticos, los valores de las instituciones y las subjetividades de quienes residen en ella.

Entre los sujetos de estudio ser jóvenes habitantes del sur de Mérida, constituye una marca que pesa porque los expone a múltiples prejuicios, estereotipos negativos y formas de discriminación, e incluso a expresiones de criminalización no solo provenientes de los discursos hegemónicos difundidos por los medios, sino por instituciones y aparatos con los que interactúan en eventos y actividades. Algunas de estas percepciones tienden a homogenizarlos con los jóvenes desacreditados del sur: los vándalos, los adictos, los delincuentes. Otras se niegan a reconocer sus potencialidades y los reducen a su condición de pobres, lo cual resulta ofensivo para su dignidad humana. En consecuencia, hay un cierto distanciamiento y rechazo hacia estos discursos, una reivindicación de sus potencialidades individuales para alcanzar sus propósitos que sintetizan en una frase recurrente: "ser alguien en la vida", al igual que la revaloración del sur, sin idealización, en el que coexisten junto a los múltiples problemas sociales, la comunicación, el trabajo, la cooperación y la solidaridad entre vecinos. 
Vista la ciudad como un espacio de enfrentamiento por las definiciones legítimas de los sentidos sociales de la vida, en los discursos de los jóvenes aparece el incumplimiento de una tarifa social en el transporte colectivo que implica a empresarios y empleados. O bien, la falta de permisos paternos para realizar ciertas actividades, la desconfianza, el trato desigual por razones de género, el cuestionamiento a las creencias personales y las decisiones injustas. De igual forma, aparecen el poco acceso a actividades culturales y recreativas que no están presentes en el sur de Mérida, y las escasas posibilidades que tienen esos jóvenes para desplazarse por la urbe por razones económicas. También están sus cuestionamientos al aparato policial y a sus profesores, no necesariamente bajo el discurso de los derechos humanos, pero sí desde aspectos esenciales constitutivos de estos, por ejemplo, la libertad, la justicia, la dignidad y la expresión de sus ideas.

Podemos concluir que en estos discursos se observan factores importantes que limitan el desarrollo y calidad de vida de estos jóvenes. Entre ellos, podemos enunciar no solamente un diseño de ciudad que los segrega y excluye, sino unos medios de comunicación que los estigmatizan, condiciones económicas concretas que influyen en su movilidad espacial, condiciones de género que presionan a las mujeres para resguardarse en el ámbito de lo privado y condiciones estructurales que los estereotipan en la categoría de "vándalos" y les restringen sus derechos a sus identidades juveniles, a sus estéticas, es decir, a su diversidad cultural.

\section{Referencias}

Barthes, R. (1993). La aventura semiológica. Barcelona: Paidós Comunicación.

Bolio Osés, J. (2014). Mérida metropolitana. Evolución histórica y rasgos actuales. Una perspectiva urbana. En: López Santillán, R. y Ramírez Carrillo, L. A. (Eds.), Crecimiento urbano y cambio social: escenarios de transformación de la zona metropolitana de Mérida. México: Universidad Nacional Autónoma de México, pp. 21-60.

Castillo León, M. T.; Guzmán Medina, V., y Lugo Pérez, J. A. (2016). El sur profundo de Mérida. Diagnóstico social y económico de dos colonias. México: Universidad Autónoma de Yucatán.

Chaves, M. (2017). Jóvenes entre el centro y la periferia de la ciudad, del Estado y de la academia. Ciudadanías, 1, pp. 79-96. Recuperado de http://ciudadanias. untref.edu.ar/pdf/Revista_Ciudadanias_n_1.pdf\#page $=81$

Coronado, G. y Hodge, B. (2017 [1998]). Metodologías semióticas para análisis de la complejidad. Australia: Institute for Culture and Society, Western Sydney University. 
Encinas Garza, J. (1994). Bandas juveniles. Perspectivas teóricas. México: Trillas.

Franco Cáceres, J. A. (13 de febrero del 2018). El modelo urbano entregado al capitalismo inmobiliario de interés transnacional en Mérida. Por Esto! Recuperado de https://www.poresto.net/ver_nota.php?zona=yucatan\&idS eccion $=1 \&$ idTitulo $=625579$

Fuentes Gómez, J. H. (2005). Espacios, actores, prácticas e imaginarios urbanos en Mérida, Yucatán, México. México: Universidad Autónoma de Yucatán.

García, G., Oliva, Y., y Ortiz, R. (2012). Distribución espacial de la marginación urbana en la ciudad de Mérida, Yucatán, México. Investigaciones geográficas. Boletín del Instituto de Geografía, 77, pp. 89-106.

Hansen, A. T., y Bastarrachea, J. R. (1984). Mérida. Su transformación de capital colonial a naciente metrópoli en 1935. México: Instituto Nacional de Antropología e Historia.

Margulis, M. (2002). La ciudad y sus signos. Estudios Sociológicos, 20(3), pp. 515-536.

Martínez, L. S. (2016). Rasgos discursivos de la configuración de territorio en textos escritos de jóvenes entre 15 y 18 años de las comunas 8 y 9 de Medellín (2013-2014). (Tesis de grado). Universidad EAFIT, Medellín, Colombia. Recuperado de http://hdl.handle.net/10972/1069

Municipio de Mérida (2011). Diagnóstico estadístico y situacional del Municipio de Mérida, Yucatán. Recuperado de http://www.merida.gob.mx/municipio/ portal/umaip/contenido/poas/diagnostico.pdf

Pérez, E., y Gamallo, P. (2014). Segregación socioespacial en una ciudad de tamaño intermedio. El caso de Mérida. En: López Santillán, R., y Ramírez Carrillo, L. A. (Eds.), Crecimiento urbano y cambio social: escenarios de transformación de la zona metropolitana de Mérida. México: Universidad Nacional Autónoma de México, pp. 61-84.

Pérez Medina, S. (2010). Segregación, recreación y calidad de vida en Mérida. México: Universidad Nacional Autónoma de México.

Quiroz Carranza, R. (2014). Ser joven en el sur de Mérida, Yucatán. Un estudio sobre derechos humanos y juventud en estudiantes de un bachillerato con interacción comunitaria. (Tesis de doctorado en Ciencias y Humanidades para el DesarrolloInterdisciplinario).México:Universidad Autónoma de Coahuila. Recuperado de http://www.doctoradoceii.mx/productoscientificos_archi vo.php?uuid=454D8DAB-88AD-F843-95BC-2C0B03A3639E

Ramírez, L. A., y López Santillán, R. (2014). Mérida: Los trabajos y los días. En: López Santillán, R., y Ramírez Carrillo, L. A. (Eds.), Crecimiento urbano y cambio social: escenarios de transformación de la zona metropolitana de Mérida. México: Universidad Nacional Autónoma de México, pp. 9-19. 
Ramírez-Kuri, P. y Aguilar, M. A. (2006). Introducción. En: Ramírez Kuri, P., y Aguilar Díaz, M. A., Pensar y habitar la ciudad. Afectividad, memoria y significado en el espacio urbano contemporáneo. España: Anthropos/UAMIztapalapa, pp. 7-12.

Ramírez-Kuri, P., y Ziccardi, A. (2008). Pobreza urbana, desigualdad y exclusión social en la ciudad del siglo XXI, una introducción. En: Cordera, R., Ramírez-Kuri, P., y Ziccardi, A. (Coords.), Pobreza, desigualdad y exclusión social en la ciudad del siglo XXI. México: Siglo XXI Editores, pp. 23-48.

Reguillo, R. (1995). Pensar la ciudad desde la comunicación. Un ejercicio necesario. En: Galindo, J., y Luna, C. (Coords.), Campo académico de la comunicación. Hacia una reconstrucción reflexiva. Guadalajara: Consejo Nacional para la Cultura y la Artes/Instituto Tecnológico y de Estudios Superiores de Occidente, pp. 109-132.

Reguillo, R. (2005 [1996]). La construcción simbólica de la ciudad. Sociedad, desastre y comunicación. México: Instituto Tecnológico y de Estudios Superiores de Occidente/Universidad Iberoamericana.

Reyes, G. (2003). Carnaval en Mérida. Fiesta, espectáculo y ritual. México/Mérida: Instituto Nacional de Antropología e Historia/Universidad Autónoma de Yucatán.

Rizo, M. (2005). La ciudad como objeto de estudio de la comunicología. Andamios, 1(2), pp. 197-225.

Safa, P. (1993). Espacio urbano como experiencia cultural. En: Estrada, M. et al. (Comps.). Antropología y ciudad. México: CIESAS/Universidad Autónoma Metropolitana-Iztapalapa, pp. 283-295.

Safa, P. y Aceves, J. (2006). La experiencia de la exclusión social y urbana en torno a la vivienda. En: Ramírez-Kuri, P., y Aguilar Díaz, M. A. (Coords.). Pensar y habitar la ciudad. Afectividad, memoria y significado en el espacio urbano contemporáneo. España: Anthropos/UAM-Iztapalapa, pp. 51-67.

Silva, A. (2006). Imaginarios urbanos. Bogotá: Editorial Nomos.

Universidad Autónoma de Yucatán (2009). Programa Educativo de Nivel Medio Superior. Bachillerato General con Interacción Comunitaria. Mérida: Coordinación General de Educación Media Superior de la Universidad Autónoma de Yucatán.

Valenzuela Arce, J. M. (1988). ¡A la brava ése! Tijuana: El Colegio de la Frontera Norte.

Vela, F. (2001). Un acto metodológico básico de la investigación social: la entrevista cualitativa. En: Tarrés, M. L. (Coord.), Observar, escuchar y comprender. Sobre la tradición cualitativa en la investigación social. México: Facultad Latinoamericana de Ciencias Sociales/El Colegio de México, pp. 63-95. 
Villafranco, G. (30 de diciembre de 2016). Ecatepec y Naucalpan, los peores lugares para vivir en México. Revista Forbes. Recuperado de https://www.forbes.com. mx/ecatepec-y-naucalpan-los-peores-lugares-para- vivir-en-mexico/

Ziccardi, A. (2008). Ciudades latinoamericanas: Procesos de marginalidad y de exclusión social. En: Cordera, R., Ramírez-Kuri, P., y Ziccardi, A. (Coords.), Pobreza, desigualdad y exclusión social en la ciudad del siglo XXI. México: Siglo XXI Editores, pp. 73-91. 